\title{
JOSÉ MARTÍ Y SU TRANSPENSAMIENTO DE RAMONA POR HELEN HUNT JACKSON: UN DIÁLOGO DE SUSTANCIA Y ESTILO ${ }^{1}$
}

\author{
POR \\ Catherine Vallejo \\ Concordia University
}

Todos hallarán en Ramona un placer exquisito: mérito el literato, color el artista, ánimo el generoso, lección el político, ejemplo los amantes, y los cansados, entretenimiento. (José Martí, Prólogo a su traducción de Ramona de Helen Hunt Jackson). ${ }^{2}$

Traducir es transcribir de un idioma a otro. Yo creo más, yo creo que traducir es transpensar... (José Martí; énfasis en el original; Prólogo a su traducción de Mes fils de Victor Hugo).

La totalidad de la obra martiana es casi inabarcable; su valor político y cultural impresionante. Entre los estudios ya abundantes sobre esta producción intelectual tan importante, en años recientes también el aspecto 'traducción' comienza a estudiarse-ver por ejemplo Lourdes Arencibia Rodríguez, Leonel-Antonio de la Cuesta, Jorge Luis Rodríguez Morell y, por supuesto, Iván Schulman, entre otros. En efecto, y como lo asevera Carmen Suárez León, se puede ver la traducción como uno de los “ejes” en torno del cual gira la poética de Martí (187), y su traducción (1888) de la novela Ramona de

\footnotetext{
1 Agradezco los aportes que a este trabajo ha hecho Ana María Kerekes, cuya disertación de maestría en 2009 (Poder by belleza de la palabra) consiste de un análisis lingüístico de la traducción martiana. Kerekes compiló en series los cambios efectuados por Martí, de cuyas listas han surgido muchos de los ejemplos utilizados en este ensayo. Asimismo quiero expresar mi agradecimiento a Maia Barreda -editora del volumen Ramona de las Obras completas de Martí que están en preparación en Cuba y quien me facilitó amplia ayuda y documentación durante nuestros diálogos productivos en el Centro de Estudios Martianos en La Habana. Y por fin, gracias también a Carmen Suárez León, amiga y compañera.

2 Ya que existen muchas y variadas ediciones de las obras de José Martí, citaré de la edición que preparara Ciencias Sociales en 1976 de sus Obras completas, donde Ramona aparece en el vol. 24.
} 
Helen Hunt Jackson (1884) como una obra que tanto al nivel explícito como de manera implícita trata de muchas de las cuestiones que preocupaban a Martí en esa época, que fue, precisamente, clave en su vida desde muchas perspectivas; de ahí que es importante "remitir las obras a su tiempo", como lo expresa Roberto Fernández Retamar acerca de la Ramona de Martí (420).

Martí vivió en los Estados Unidos, más o menos continuamente, desde 1880, y utilizó sus muy populares artículos periodísticos - publicados especialmente en México (donde aun tenía lazos estrechos en la comunidad intelectual) y Argentina- como un instrumento para informar a los pueblos latinoamericanos sobre las culturas 'otras', y especialmente la norteamericana. En esos artículos advertía -en lenguaje que por cuidadoso no fuera menos convincente- de las incursiones siempre más frecuentes y atrevidas en asuntos latinoamericanos por parte de los norteamericanos. En esos momentos estaba Martí apartado de los esfuerzos militares que gerenciaban Antonio Maceo y Máximo Gómez por obtener más independencia para la isla de Cuba, pero continuaba sus crónicas y sus interpretaciones de los eventos que consideraba de interés para los latinoamericanos. ${ }^{3}$ Fue observador intenso de la vida intelectual de los Estados Unidos, y asistió a las lecturas de los poetas Whitman, Emerson y otros, habiendo publicado é mismo en 1885 su única novela, un género que él no apreciaba. ${ }^{4}$

A través de un examen de los cambios estilísticos que Martí efectúa al estilo mayormente descriptivo de la novela de Hunt Jackson, así como por un estudio de tratamiento lingüístico martiano de tres temas particulares que se presentan en la novela -la ideología (sus expresiones sobre "nuestra América"), la cuestión de la raza (sobre todo los indígenas), y la mujer-este breve trabajo ${ }^{5}$ intenta proveer evidencia en apoyo de dos cuestiones: de que la Ramona de Martí en verdad conforma un importante eje de su producción y pensamiento, y cómo, al efectuar algunos cambios sutiles (procedimiento que Antoine Berman llamaba la 'manipulación de significantes' [285]) que no traicionan

3 La complejidad continental de muchos de los eventos de esa época le fue de especial impacto durante la conferencia panamericana de 1889, cuando estaba preparando la segunda edición de su Ramona - México. Celcbado en Washington, este evento y esápoca le callo

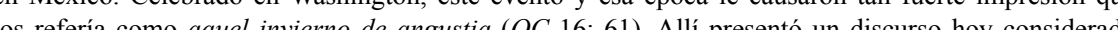
con como uno de sus textos clave y titulado "Madre América" (OC 6. 133Sarracino ofrecen detalles de la biografia martiana para esa época.

Aun en 1880, en una carta a su hermana Amelia, Martí menciona que la novela es un género 'vulgar' “apenas hay novela que no lo sea” (20: 287); más tarden en el prólogo a su única novela Lucía Jerez o Amistad funesta, (1885) escribe que "El género no [me] place,... porque hay mucho que fingir en él, y los goces de la creación artística no compensan el dolor de moverse en una ficción prolongada; con diálogos que nunca se han oído, entre personas que no han vivido jamás...." (18: 192).

Rodríguez Morell sugiere que haría falta una monografía para estudiar la traducción martiana de Ramona para apreciar las complejidades de las cuestiones presentades. La novela de Hunt Jackson ha sido vertida en muchas lenguas; las versiones al alemán y al francés fueron anteriores a la martiana.

Revista Iberoamericana, Vol. LXXIX, Núms. 244-245, Julio-Diciembre 2013, 777-795 ISSN 0034-9631 (Impreso) ISSN 2154-4794 (Electrónico) el texto original, Martí apuntó la traducción hacia sus propias perspectivas sobre estas cuestiones, así mejorando, además, el original de múltiples maneras. Es decir, y en resumen, este trabajo intenta mostrar cómo la traducción de Martí constituye una red dialógica fuerte en torno a su propio pensamiento -diálogo entre la novela y estos pensamientos, y, en fin, entre los pueblos norteamericano, mexicano e indígena, entre los rasgos de la expresión escritural norteamericana y latinoamericana de su época.

Esta traducción martiana puede verse, en efecto, como una "simbiosis del arte y de la ideología martianos [...] un diálogo, una especie de subtexto" $(1990,290)$, en las palabras de Iván Schulman, en la cual, a través de las lagunas, silencios o huecos que existen entre el texto original y su traducción, ${ }^{6}$ Martí crea una 'zona de contacto', un territorio marginal o límite de desplazamientos dinámicos y de palimpsesto que no solo constituye una escritura 'sobre' el original, sino que también actúa estratégicamente con los elementos del original para crear una obra propia martiana. ${ }^{7}$ En el epígrafe citado del prólogo de su traducción de Mes Fils del poeta francés Víctor Hugo, Martí había dicho también que "traducir es pensar como [el autor], impensar, pensar en él" (24: 16); aunque esta afirmación puede aplicarse a sus traducciones de Emerson, Whitman y el mismo Hugo, en su Ramona, el ‘trans-pensamiento' es mucho más que un movimiento personal de autor a autor, ya que Martí se extiende fuera de sí mismo hacia el pensamiento cultural de todo el continente "nuestro".

En efecto, la mera existencia de las dos versiones de esta novela es dialógica, comenzando con las circunstancias extratextuales de un hombre hispánico de tradición católica y agitador por la independencia cubana, que no gustaba de la novela como género literario ni de mujeres que trabajaran en campos no tradicionales, que tradujo una novela sobre la situación de los indígenas en un territorio que había sido latinoamericano y que él nunca conoció -y la novela escrita por una escritora anglo-americana y protestante que apenas hablaba algunas palabras del español pero que viajó extensamente en la región novelada. Es verdad que ambos escritores destinaban su obra como "una arma de lucha" contra un 'otro', como lo ha dicho Mary Cruz de la versión martiana, y si el término 'traducir' refiere a la transferencia de una cultura a otra, las primeras preguntas que deben hacerse son: “¿quién traduce?” y “¿cuál es el ‘otro’?”

Helen Fiske (1830-1985) fue la hija de un religioso protestante y de una maestra de lenguas clásicas; generalmente se la conoce como Helen Hunt Jackson por los apellidos de sus maridos. Después de asistir a una conferencia ofrecida por un indio ponca en 1879 comenzó a interesarse vivamente en la 'cuestión indígena' en los Estados Unidos,

Lomas nota el hecho de que "To miss the gap between the original and the translation of Ramona, a discrepancy that scholarship on Martí and Jackson has yet to consider fully, is to minimize the differences between the location and investments of the white North American woman reformer from New Englan the migrant Latino revolutionary" (265).

Lomas ve la traducción martiana como "a strategic response to an imposed imperial language" (223). 
y en 1881, después de haber investigado y entrevistado numerosas fuentes, publicó un resumen del tratamiento gubernamental de siete tribus indígenas, con el título de $A$ Century of Dishonor: A Sketch of the United States Government's Dealings with Some of the Indian Tribes, texto del que repartió, costeado por ella misma, un ejemplar a todos los representantes del gobierno (Phillips 234). Como consecuencia de esa obra, fue invitada a escribir artículos periódicos sobre California en la revista prestigiosa Century Illustrated Magazine $e^{8}$ y por varios meses en1882 y 1883 cruzó el territorio sureño del estado, de nuevo entrevistando a muchos individuos y grupos de indígenas. Solicitó nombramiento como uno de los dos 'representantes especiales' del gobierno encargados de investigar las condiciones de la vida de los indígenas de California, situación que le alarmaba con creciente intensidad. ${ }^{9}$ No era que estuviera en contra de la presencia estadounidense en California como tal -de hecho, vio este territorio como el 'imperio' de América- pero sí abogaba por una presencia más sensible a los habitantes de la región (Phillips 241), en especial con respecto a los indígenas y los mexicanos, los dos grupos de su mayor interés. Su Report on the Condition and Needs of the Mission Indians enviado al Director de Asuntos Indígenas y escrito con Abbott Kinney -que hablaba español y fue su co-'representante'- se publicó 1883 (ver Phillips 239-240). Constaba éste de once recomendaciones para mejorar la calidad de vida de los indígenas, girando en torno a la necesidad de que el gobierno acatara los derechos ya otorgados a los indígenas; y de nuevo envió copias a amigos de importancia (Phillips 250). Para entonces Hunt Jackson se había convertido en agitadora militante en pro de los derechos de los indígenas cuya población en California se había reducido en un 80\% en tan sólo los diez años de la adquisición del territorio por los norteamericanos (Phillips 245). Cuando de nuevo su informe no tuvo el efecto deseado, Hunt Jackson decidió tratar otro recurso: en vez de una presentación de hechos y datos, produciría una novela, un género que ya tenía mucha popularidad y que llegaría a un público mucho mayor. ${ }^{10}$ Escribió Ramona. A Story en tres meses a principios de 1884, en un cuarto de un hote en Nueva York, y la publicó en folletín en la revista Christian Union ese mismo año. ${ }^{11}$

8 Ver los comentarios que hace Martí sobre esta revista en 1884: “[...] repertorio de artes y letras, de todos los tiempos, de forma exquisita y amplio espíritu, vástago natural de la nueva época, [...] brillante y ameno [..]" (13: 430); ver también sus comentarios sobre los artículos que solín aparecer en la revista

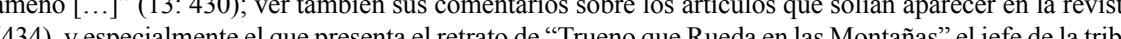
Nez Perce ( $447 \mathrm{ss}$ ), todos los artículos fechados en 1884 .

9 Ver The Century Magazine XXVI/4 "The Present condition of Mission Indians in Southern California" (August 1883)::511-529.

Aun antes de comenzar la novela, Hunt Jackson le escribió a un amigo: "If I could write a story that would do for the Indian a thousandth part what Uncle Tom's Cabin did for the Negro, I would be thankful the rest of my life" (citado en Phillips 252).

"El éxito popular de la novela fue inmediato y grande. Dirigida a la nueva y alfabetizada clase media, vendió 250,000 ejemplares, su popularidad sobrepasada tan sólo por La cabaña del Tío Tom (de la Cuesta 91). Como lo explica McKee Irwin, sin embargo, "Instead of provoking an outcry over the treatment of

17. Revista Iberoamericana, Vol. LXXIX, Núms. 244-245, Julio-Diciembre 2013, 777-795 $\begin{array}{lll}\text { ISSN 0034-9631 (Impreso) } & \text { ISSN 2154-4794 (Electrónico) }\end{array}$
Dado el ambiente casi completamente hispano-indígena de esta novela y su(s) lenguaje(s), hasta cierto punto podemos o debemos ver la obra de Hunt Jackson como siendo ya una traducción - de lengua y cultura- en la cual Helen Hunt Jackson se constituye como el 'otro' de los sujetos de la narrativa. La obra presenta aparentes torpezas de estilo casi como si fueran una exotización en el proceso de traducción, que pueden verse también como señales de este ser 'otro', la autora. Esta 'narrativa' o 'cuento', como dice el subtítulo, tiene lugar en California, territorio adquirido en 1848 por los Estados Unidos en el tratado Guadalupe - Hidalgo después de la conclusión de una guerra provocada con México y su territorio en el cual los habitantes mayoritariamente eran mexicanos de habla española, e indígenas de varias lenguas.

Así como fue el caso de los muchos miles de mexicanos que vivían en la región, después de la guerra y la ocupación Americana, la señora Moreno de la novela se ha quedado viviendo en su hacienda-siempre "more proudly, passionately, a Spaniard..." según reza (21) (traducido por Martí, con ímpetu de corrección, como "Cada vez... más mexicana..." [224])- junto con su hijo Felipe y con Ramona, una joven huérfana a quien ha adoptado, mestiza de ojos azules e hija de una mujer indígena y un irlandés. Ramona y "Alessandro", uno de los indígenas que trabaja en la hacienda en época de esquila, educado por los franciscanos de las misiones y excelente violinista, se enamoran. Alessandro le llama a Ramona 'Majel', nombre que la novela afirma quiere decir torcaza en la lengua de la tribu de Alessandro (Hunt Jackson 124). La señora Moreno se opone a este amor con virulencia, y Ramona y Alessandro salen escapados de su hacienda, pasan una noche virtuosa en las montañas y son casados por un cura el día siguiente. Regresan a Temecula, el pueblo de Alessandro y lo encuentran destruido por granjeros americanos. El matrimonio indígena-mestizo emprende una vida de labores duras y de pobreza, dificultada por el racismo y la brutalidad de los hacendados americanos de la región. Su joven hijita "Eyes of the Skye" (252) se muere, y Ramona da a luz a otra niña, a quien nombran también Ramona. Con el tiempo y las dificultades de la vida, Alessandro se vuelve loco y es asesinado por un hacendado quien sin causa le acusa de

Native Americans, the novel won the affection of many faithful readers for its romantic plot... centere around Ramona and not Native American Alessandro" y las injusticias cometidas contra la población indígena (542); en efecto, no fue la historia de los indios lo que atraía a los lectores, sino el relato (" $A$ story") de una joven inocente. La popularidad ha llegado a tal extremo que se puede hablar hasta de un "fenómeno Ramona" ya que ha dado lugar a un desfile anual desde 1923 (en los que apareció Raquel Welch una vez como Ramon), con festivales y rutas de turismo de tipo 'Ramon slept here'. Se le ha . Pick (Des Rio (1928) y Loetta Young (1936) -algun au dispoin después del 2000 se presentó una telenovela en Mexico-(McKee Iwin). Hubo 22 ediciones publicada para el año 1900; ahora hay unas 160; se citará de la impresión de 2002 que hizo Penguin Books en 1988. La versión martiana también fue un gran éxito, vendiendo 15,000 ejemplares, especialmente en La Habana y México (Martí 20: 114)

Revista Iberoamericana, Vol. LXXIX, Núms. 244-245, Julio-Diciembre 2013, 777-795 ISSN 0034-9631 (Impreso) ISSN 2154-4794 (Electrónico) 
robo. El hijo de la Sra Moreno, Felipe, quien siempre estuvo enamorado de Ramona, la ha ido buscando y al encontrarla viuda regresa con ella a la hacienda de su madre. Aunque Ramona lo considera como un hermano, Felipe la convence de casarse con él. La Sra. Moreno se muere y Felipe hereda su propiedad, pero cuando sigue la presión de los hacendados contra ellos, venden la hacienda y el matrimonio ahora de mexicano y mestiza, parten para vivir en México -lugar donde, aunque ambos son herederos de su tradición, ninguno de los dos ha visitado siquiera. ${ }^{12}$

Esta conclusión a la novela puede verse de maneras diferentes (ver McKee Irwin), pero como lo indica Laura Lomas (271), la traducción martiana de un pasaje clave a final de la narrativa subraya la diferencia del concepto de 'raza' que existió en Martí y en la autora Hunt Jackson. Sirva un breve examen de un párrafo como aclaración: Hunt Jackson escribe: "[...] And as she [Ramona] spoke, Felipe understood by a lightning intuition, and wondered that he had not foreknown it, that she would spare her daughter the burden she had gladly, heroically borne herself, in the bond of race" (359). Mart elimina la "lightning intuition" de Felipe, y más bien le hace cuestionar su propia falta de comprensión; más importante, Martí también elimina el término "gladly" con respecto a lo que Hunt Jackson llama la carga del "bond" de la raza y lo transforma en una libertad del "peligro" de la raza: "[...] Y conforme hablaba [Ramona], iba Felipe asombrándose de cómo no había entendido antes que Ramona quisiese tener libre a su hija del peligro de raza que había afrontado ella con tanto heroísmo" (500). La traducción es clara evidencia de la creencia por parte de Martí en el racismo de los Estados Unidos, el que colocaría a la hija mestiza en el mismo peligro que Ramona tuvo que confrontar, y el que había sido la causa de la muerte de Alejandro.

Es evidente que fue, precisamente, el contraste entre los dos caminos vitales y dos maneras de pensar lo que constituyó la atracción de la novela para Martí, a la que calificó de "un libro bueno, y muy mexicano" (20: 118). Además de ver la novela como un primer paso hacia una empresa editorial viable (113), sus motivos por la traducción de la novela fueron mayormente políticos -es decir, ideológicos, culturales y sociales-y especialmente como instrumento para advertir a América (y de nuevo, especialmente a México y Cuba) de lo que podía ocurrir, o aun ocurriría, a los pueblos de esas regiones si los Estados Unidos tuvieran medios de entrar en esos territorios. "[U]na campaña de propaganda activa y discreta en beneficio de México" fue lo que Martí vio como necesidad urgente (20: 103); la novela traducida formaría parte de este plan:

\footnotetext{
12 Los detalles presentados en la biografía de Helen Hunt Jackson indican claramente que muchos de lo incidentes relatados en la novela se basan en eventos históricos que se le contaron o que ocurrieron

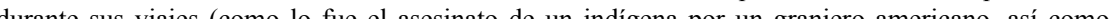

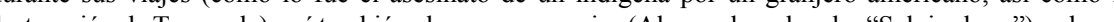
, así también algunos personajes (Alessandro, el padre "Salvierderra") se basa en personas históricas (Phillips 247-254).
} ISSN 0034-9631 (Impreso)

Vol. LXXIX, Núms. 244-245, Julio-Diciembre 2013, 777-795 ISSN 2154-4794 (Electrónico)
Pensé que a México [Ramona] llega muy a tiempo, porque sin excitar la pasión contra el americano -lo que en la autora sería traición fea, y en mí imprudencia y en cierto modo entrometimiento- su lectura deja en el ánimo inevitablemente, sin violentar la lección ni insinuarla siquiera, la convicción de que al mexicano no le iría bien en manos de Norteamérica (20: 113).

[Es] una obra que en nuestros países de América pudiera ser de verdadera resurrección [...] (Prólogo a Ramona, 203) $)^{13}$

Leonel de la Cuesta ha dicho que en Ramona Martí utiliza "la traducción como defensa frente al entrometimiento foráneo" (101); mejor, según lo veo, sería llamar la traducción un instrumento ideológico de persuasión, de carga dialógica. Así como a través de los siglos se ha utilizado la traducción como instrumento para promover la cultura metropolitana en las regiones conquistadas por Occidente (de la Cuesta 85), con su traducción Martí apunta el instrumento del colonizador en contra de éste. En la traducción de Martí, el subtítulo original de Hunt Jackson: "A Story" se transforma en Novela americana, por lo cual Martí ofrece el continente entero como territorio narrativo en una apropiación-colonización textual. ${ }^{14} \mathrm{Su}$ versión no sólo se hace más hispanoamericana en términos territoriales, dirigida a lectores hispanoamericanos; para Martí, por supuesto, este territorio es 'nuestro'. Así, en su prólogo, refiere repetidamente no sólo a la novela como 'nuestra', sino también que ella refleja "nuestra elocuencia $[\ldots]$ nuestras tunas $[\ldots]$ nuestras noches $[\ldots]$ nuestras ipomeas $[\ldots]$ paisajes, drama y caracteres nuestros $[\ldots]$ nuestras haciendas $[\ldots]$ nuestros viejos solares campesinos [...]" (Martí, Ramona 204) -en clara oposición a no ser la novela norte-americana. Los comentarios que hace a su amigo Mercado con respecto a la traducción francesa que se publicó en 1887, también llaman la atención: La conquête américaine de l'Amérique, dice Martí, fue el subtítulo agregado en la versión francesa, "impropiamente, aunque con algún derecho..." (20: 122).

A estas alturas es interesante examinar las perspectivas que Martí guardaba acerca de lo que sería la 'traducción', perspectivas que tan sólo explicitó en pocas instancias regadas a través de la totalidad de su obra, en textos, cartas y apuntes. Es más interesante aun si recordamos que la traducción en efecto formó un componente mayor de su labor profesional, en especial en su trabajo de corresponsal. Grandes partes del contenido de sus artículos periódicos publicados en México y Argentina -sus Escenas

13 Porque insistía en traducir la novela de Hunt Jackson, Martí mismo tuvo que financiar el proyecto y cortar sus lazos con la editorial Appleton por la cual ya había hecho varias traducciones, incluyendo la novela Called Back de Hugh Conway (pseud. de Frederick John Fargus), publicada con el título Misterio en 1886 y que fue, según Martí, "una soberana bellaquería $[\ldots]$ un desastre" $(O C 24,113,114)$

14 De la misma manera, Martí cambia los nombres de varios personajes para que sean más 'hispánicos'; Alessandro se convierte en Alejandro, Father Salvierderra (!) adquiere con Salvatierra un nombre de ricos ecos simbólicos; Luigo se hace Luis y Carmena, por supuesto, Carmen.

Revista Iberoamericana, Vol. LXXIX, Núms. 244-245, Julio-Diciembre 2013, 777-795 ISSN 0034-9631 (Impreso) ISSN 2154-4794 (Electrónico) 
norteamericanas - habrán dependido en mayor medida de adaptaciones y traducciones de sus propias lecturas de publicaciones norteamericanas: "obligatoriamente [...] una operación incesante de traducción implícita o explícita", como lo expresa Carmen Suárez León (182), o, para decirlo en la metáfora utilizada por Martí: una manera de zurcir partes de textos diferentes. ${ }^{15}$ Con respecto al proceso de la traducción como tal, queda claro que Martí cree en la estrategia de 'naturalización', la que produce el texto traducido como si hubiera sido escrito 'naturalmente' en la lengua meta y eso, de hecho, en contraste con las expresiones 'exotizantes' que utiliza Hunt Jackson en ocasiones en el original inglés, y que resultan bastante torpes. El deber de un traductor, dice Martí, "es conservar su propio idioma [...][T]raducir es pensar en español lo que en su idioma ellos [los autores] pensaron [...]” (24: 16). La traducción de Ramona se ve en concordancia con la opinión que Martí expresó en una carta a "mi María" [Mantilla] en 1895: "La traducción ha de ser natural, para que parezca como si el libro hubiese sido escrito en la lengua a que lo traduces, que en eso se conocen las buenas traducciones" (20:217). Esta convicción se hará muy evidente en su Ramona, la que, en palabras de Ana Maria Kerekes repatriates la novela (37) para que así pertenezca en/a la expresión cultural latinoamericana. Martí también cree que "[...] Traducir es estudiar, analizar, ahondar Cavé en cuanto pude" como lo dice de su traducción de Victor Hugo (24: 16) cavar en los contextos de la obra original, su cultura, lengua, y, sin duda, en las profundidades del traductor ("dar de sí la esencia")

A nivel implícito se distinguen una cantidad de cuestiones sutiles que pueden verse en relación dialógica, dentro de la novela misma, en su lenguaje, y en su relación con la vida de Martí durante esos años. La traducción como proceso es mediadora entre culturas a través del lenguaje, y así desestabiliza la primacía del texto original y, a partir de su ser 'otro' se transforma en creación original. Lo que Octavio Paz ha afirmado acerca de la traducción puede aplicarse claramente a la labor de Martí sobre Ramona: "Cada traducción es, hasta cierto punto, una invención y así constituye un texto único" (67). Iván Schulman, que escribe más específicamente sobre las traducciones martianas, las llama "trans/texts", un modo ensayístico subtextual conformado en narrativas novelística (1990 y 1995); en efecto, para Martí Ramona se convirtió en una expresión de su propio contexto vital y su pensamiento con respecto a las cuestiones que le preocupaban en esa época, así como una expresión claramente dirigida a su lector hispanoamericano por cierto (Barredas Sánchez 10).

Varios teóricos en el campo de la traducción ofrecen listas de estrategias que "deforman" y que resultan en la restitución del significado por embellecimiento con

\footnotetext{
${ }^{15}$ En una carta de diciembre de 1882 a Bartolomé Mitre, y con referencia a sus "Cartas" para el periódico argentino La Nación, Martí explica su proceso de escritura periodística como zurcir, término que aclar como uniendo "los diversos vientos [...] henchido el juicio de pareceres distintos [...] dejarlos hervir, y dar de sí la esencia [...] ¿No le place esta manera de zurcir mis cartas?” (9: 17).
}

Revista Iberoamericana, Vol. LXXIX, Núms. 244-245, Julio-Diciembre 2013, 777-795 ISSN 0034-9631 (Impreso) ISSN 2154-4794 (Electrónico) el fin de conformar la producción textual traducida más clara, elegante, pura y fluida (Berman 288, 296-97). Estas prácticas incluyen, entre otro, la racionalización, la destrucción de los códigos lingüísticos, de las redes vernáculas o de su exotización, añadidos y omisiones, la adaptación, modulación, sustitución, el empobrecimiento cualitativo y cuantitativo, el enriquecimiento ... (Berman 288-292; de la Cuesta 88). A estas listas se les puede considerar como de connotación negativa; refieren a traducciones que son 'manipuladas', que no son 'literales'. A pesar de la insistencia de Mary Cruz en "el cuidado que puso [Martí] en ceñirse al original", debe decirse ab initio que la traducción que hace Martí de Ramona no es 'literal' en ningún sentido. Sin embargo, como se verá, sí es consecuente con la cultura californiana (mexicana) y con las perspectivas martianas sobre cuestiones de estilo, de género (novelesco y femenino), y con su ideología política. Hace uso frecuente de la síntesis, a través de la estrategia de la adaptación; omite de manera cuantitativa pero embellece cualitativamente, destruye redes vernáculas y códigos lingüísticos, sustituyendo un lenguaje y un estilo que se conforman a su propio pensamiento sobre un gran número de cuestiones. Así como lo hizo Helen Hunt Jackson misma, él vio Ramona como un exemplum o relato moral -aunque con un mensaje un tanto diferente del que pensó la autora americana-y así se convierte la novela en un instrumento cuasi pedagógico, algo que al fin propuso de manera explícita como proyecto de importancia después de la publicación de Ramona, a través de su revista infantil La Edad de Oro en 1889, la que también dependía de manera sustancial de la traducción, que él mismo efectuaba.

Es ya lugar común decir que las lenguas romances necesitan 'más palabras' que el inglés para expresar las mismas cosas; por tanto, generalmente los textos traducidos del inglés al francés y al español ocupan 'más espacio' que el original. Ocurre lo contrario en el caso de la Ramona de Martí, que es, en efecto, más breve que el original de Hunt Jackson. Además de la omisión de palabras, frases, párrafos y aun páginas enteras, Martí 'edita' el estilo de Hunt Jackson al reducir pasajes que poco tienen que ver con el relato principal, creando así imágenes muy vívidas que producen un impacto mayory resultando en un conjunto de más fluidez narrativa y de tono más 'moderno', con el resultado de que la versión martiana se lee aun hoy con facilidad y placer, mientras la expresión de la original se percibe como anticuada: verbosa, convencional y ampulosamente victoriana, con narración torpe, descripciones de un sentimentalismo exagerado y sintaxis artificiosa. Los siguientes pocos párrafos darán una idea de los procedimientos traductológicos generales usados por Martí:

A bad beginning did not make a good ending of the señora Moreno's sheep shearing this year. One as superstitiously prejudiced against Roman Catholic rule as she was in favor of it, would have found, in the way things fell out, ample reason for a belief that the señora was being punished for having let all the affairs of her place come to a stand-still, to await the coming of an old monk. But the pious señora, looking at the

Revista Iberoamericana, Vol. LXXIX, Núms. 244-245, Julio-Diciembre 2013, 777-795 ISSN 0034-9631 (Impreso) ISSN 2154-4794 (Electrónico) 
other side of the shield, was filled with gratitude that, since all this ill luck was to befall her, she had the good Father Salvierderra at her side to give her comfort and counsel (Hunt Jackson 59)

No tiene por qué acabar bien lo que empieza mal. Los herejes hubieran dicho que todo aquello pasaba por encapricharse la señora en demorar la esquila hasta que llegara un fraile viejo. Pero ella decía que, puesto que el mal iba a suceder, era gran bondad de Dios tener el Padre al lado. (Martí 257)

The people are corrupted. Keeps your father the worship in the chapel still, and does a priest come often to the village? (65)

-Los tiempos, hijo, los tiempos. Se nos ha llenado la tierra de herejes. ¿Todavía tienen uds. cura en su capilla? (Martí 261)

...in the early part of this century, under the rule of the Spanish and Mexican viceroys, when the laws of the Indies were still the law of the land, and its old name "New Spain", was an ever present link and stimulus to the warmest memories and deepes patriotisms of its people. (21)

[...] aprincipios delsiglo [...] cuando aun llamaban Nueva España a México (Martí217)

Dadas sus simpatías por lo mexicano, y su objetivo de vender la novela especialmente en México, Martí tendría la tendencia a exhibir a los mexicanos de manera favorable, aun donde Hunt Jackson se acerca a la crítica. El uso dominante del gerundio en la version original: "during the height of despoiling and plundering of the Missions [by the Mexicans] under the secularization Act [...]" (21) se transforma en voz pasiva (la que no expresa sujeto-agente y no es muy usada en español): "cuando fueron devueltas al siglo las propiedades del templo [...]" (Martí 224) sin referencia alguna a la violencia implícita en el vocabulario del original.

En general, Martí efectúa cambios para acomodar pensamientos y prácticas culturales diferentes, y para expresar una mayor intensidad afectiva por parte de los mexicanos (latinoamericanos, vale decir). Para tal fin, se insertan palabras de mayo impacto emotivo, pero Martí también utiliza la práctica de cambiar la narración simple, o la "deadpan narration and detached voice", como lo expresa Laura Lomas (267), por expresiones cuasi vocativas exclamatorias, como si fuera discurso indirecto libre, y así produce un relato más vivo, cambia el tono y, al romper la monotonía del estilo descriptivo, inserta un subtexto que vierte sobre la eficacidad de diferentes formas de narrar, así como, posiblemente, sobre el carácter emotivo del pueblo latinoamericano:

This last outrage was too much for the Gonzaga blood to endure; the señora never afterward left her apartment, or spoke to her husband. (52-53)

2017 Revista Iberoamericana, Vol. LXXIX, Núms. 244-245, Julio-Diciembre 2013, 777-795 ISSN 0034-9631 (Impreso) (EST)ectrónico)
¡Mejor no salir jamás de su habitación, que asistir en la propia casa a su ignominia! (24: 232)

It was this which made his journey heavy-hearted, and made him feel, in approaching the señora Moreno's, as if he were coming to one of the last sure strongholds of the Catholic faith left in the country. (63-64)

Por fin iba a descargar el corazón en la casa de la señora Moreno, donde la te tenía aun segura fortaleza! (24: 239)

Alessandro's eyes fastened on the gold. How he longed for an abundance of those little shining pieces for his Majella! (221)

¡Oro para su Majela! (24: 389)

They were utterly disheartened, broken-spirited. (329)

'Muerte, casas vacías, desgracia, muerte! (24: 481)

En efecto, y como lo indica Ana Maria Kerekes, las numerosas 'adaptaciones' llevadas a cabo por Martí en este respecto, otorgan al texto una calidad 'oral' $(30,40)$, oralidad que sería característica de la efímera humanidad, pero que, a través de la omisión de los verbos, también provee una calidad atemporal que legitima la permanencia (de la cultura latinoamericana), fuera del tiempo. Este tipo de adaptación por parte de Martí también crea un cambio de perspectiva, desde una narración impersonal que adscribe sentimientos a los personajes a expresiones emotivas que parecen surgir directamente de una voz humana, haciendo 'presente' esa humanidad. Así, donde en Hunt Jackson ocurre alguna indicación de pensamiento por parte de un personaje, con frecuencia Martí cambia el modo descriptivo al del discurso indirecto, y aun con exclamaciones o preguntas retóricas que resultan en un relato que es más breve pero de más efecto como expresión y, de nuevo, podría decirse, expresión más (latino)americana ("nuestra") Son extremadamente numerosas las manifestaciones de esta estrategia; valgan algunos ejemplos:

The details of the 'nothing' she proposed to do, slowly arranged themselves in he mind. (155)

¡Nada! (24: 334)

She though the best thing which could happen, would be that the Indian should never come back. (167)

Revista Iberoamericana, Vol. LXXIX, Núms. 244-245, Julio-Diciembre 2013, 777-795 ISSN 0034-9631 (Impreso) ISSN 2154-4794 (Electrónico) 
¡Bueno, pues!: ;que el indio no volviese nunca! (24: 344)

... the look on her face gave Alessandro a new pang. He, too, felt as if exiled afresh in leaving the spot. $(210)$

Alejandro, afligido con el pesar de Ramona, sufría como quien sale echado de la patria. ¡Aquella era otra vez la pena con que salió de Temecula! (24: 380)

To both Ramona and Alessandro it came like an omen. (208)

¿Qué habian de creer Ramona y Alejandro [...] sino que aquel era un mensaje...? (Martí 378)

Ramona was broken down with grief at the thought of Felipe's death. (63)

¡Morirse Felipe! (24: 259)

Ramona's lip quivered, and her eyes with the tears which no other of the señora's taunts had been strong enough to bring. (135)

Esa sifue tortura para Ramona! ¡Eso síque le trajo las lágrimas a los ojos! (Martí 317)

She wondered that the girl had not more pride than to let her wretchedness be so plainly seen. (167)

¿Cómo dejaba ver Ramona así su pena? (24: 344)

Heart-sick, Felipe went away. (330)

iAy, no era ella! (24: 481)

La perspectiva martiana sobre las mujeres está en concordancia con la Ramona retratada en la novela de Hunt Jackson, y también se transmite en sus modos traductivos. A partir de los estudios que ahora se efectúan sobre 'Martí y su visión de 'la mujer'-como lo es un ejemplo notable la obra reciente de Mayra Beatriz Martínez ${ }^{16}$ - queda claro que Martí ideaba La mujer, es decir, un tipo femenino tradicional, que fundamentalmente era maternal. En su página introductoria a La Edad de Oro establece diferencias genéricas muy claras para niñas y niños: "el niño crece para caballero, y la niña nace para madre"

\footnotetext{
Aunque esta estudiosa encuentra contradicciones y problematizaciones en la perspectiva martiana sobre las mujeres, indica que "[l]os arquetipos de 'lo femenino" serán indiscutiblemente, los más conspicuos" (13). Ver también Oscar Montero (35-48) ISSN 0034-9631 (Impreso) Vol. LXXIX, Núms. 244-245, Julio-Diciembre 2013, 777-795 ISSN 2154-4794 (Electrónico)
}

(Martí 18: 301), y los pocos textos que Martí dedicara específicamente a la mujer tratan mayormente con este aspecto, especialmente como se relaciona a lo patriótico, las idealizadas madres de la patria. Aunque mestiza y por tanto característica de la visión martiana de Latinoamérica, y aunque su Ramona es una "mestiza arrogante" que responde a la "llamarada de la rebeldía," también ella "va cosida a su indio..." (24: 204), y Martí mantiene la timidez exhibida por la Ramona de Hunt Jackson. En un relato de "true love triumphant... adapted from Jean Jacques Rousseau's dream of noble savages [set in a] pure 'Cinderella"' story (Dorris v, xi), el personaje Ramona no se desarrolla; se le presenta como perfecta desde el mismo principio de la novela-sumisa, idealizada, casi mítica e irreal-y así en concordancia con los mismos principios martianos sobre la mujer.

Donde Hunt Jackson presenta a Ramona desde una perspectiva diferente, más progresista, Martíno la sigue en su traducción. Muy al principio de la novela Hunt Jackson describe a Ramona; era ésta "to the World at large, a far more important person than the Señora [Morena] herself. The Señora was of the past; Ramona was of the present" (23). Aunque esta frase se presenta como de importancia ideológica para las ideas martianas al establecer a la heroína mestiza como una presencia viva y contemporánea que podría actuar en la defensa de su gente, este aspecto del personaje no se traduce, sino que Martí utiliza su práctica de síntesis: "Ramona era una gloria" (Martí 227), erradicando con esta expresión de idealización generalizada el estatuto de Ramona como mujer viviente casi desde el principio del relato. El párrafo de Hunt Jackson continua: “[...] the shepherds, the herdsmen, the maids, the babies, the dogs, the poultry, all loved the sight of Ramona; all loved her [...]" (23). Aunque Martí traduce la lista que hace Hunt Jackson de los representantes de la vida natural e inocente -incluyendo los animales y los niñoscambia el tipo de amor expresado al final, diciendo que "todos estaban enamorados de Ramona [...]" (Martí 227) y transforma a Ramona en una mujer bella e idealizada de quien todos se enamoran. Es también interesante ver cómo Martí cambia o aun omite pasajes que tratan de la fuerza mental y la inteligencia femeninas, como los siguientes:

She would be wise, Alessandro was sure. (189)

Cuanto debiera y pudiese: de eso estaba Alejandro seguro. (24: 363)

Ramona knew many things that Alessandro did not. (289). [no traducido]

Majella is wiser than the dove! Cried Alessandro. She has seen what is the best thing to do! (303). [no traducido]

Martí utiliza la misma estrategia con respecto a los indígenas, donde las expresiones que podían verse como juicios negativos se cambian o se omiten:

Revista Iberoamericana, Vol. LXXIX, Núms. 244-245, Julio-Diciembre 2013, 777-795 ISSN 0034-9631 (Impreso) $\quad$ ISSN 2154-4794 (Electrónico) 
I think they ought to have made the Indians listen. (231) [no traducido]

...at each of these places he found Indians' miserable, half-starved creatures, most of them... (324). [no traducido]

"That's a handsome squaw when she's mad" (306)

"Y buena moza que es la mujer cuando se enoja" (24: 461)

Asimismo, en un gran número de casos Martí inserta el vocablo "indio" donde el original tiene, por ejemplo: "my good fellow" (263), "head shepherd" (111), "that beggar" (297). Y donde Hunt Jackson utiliza una expresión denigrante como "all injuns" (294), Martí propone estos pobres indios de Dios (24: 451), y "the homeless man" (206) se transforma en el indio errante (24: 376). La expresión cargada de negativa y condescendencia "this simple-minded unlearned man" para referir a Alessandro (48) se transforma en el sencillo Alejandro (24: 247), una presentación mucho más humana $\mathrm{y}$, de hecho, positiva. Tanto en el caso de sus versiones relacionadas a la mujer como a as que vierten sobre los indígenas, el tratamiento traductivo martiano revela matices subtextuales, pero en contraste con las características de Ramona, su versión de cuestiones relacionadas con lo indígena adquiere un efecto más positivo que el original.

Martí refleja el tema patriótico especialmente, y significativamente, a través de indicaciones de origen y referencias a tierra y pueblo; por ejemplo donde Hunt Jackson simplemente utiliza el artículo, Martí pone el posesivo, enfatizando así el sentimiento, aun fuerte, de que el territorio (California) aun pertenece a los mexicanos o a los indígenas, es decir a "nuestra América" (ver también Kerekes 44):

These are some of the Temecula people. (244)

Estos son gente de mi Temecula (24: 405)

The way things were going in the land for whose sake he had died. (23)

[...] al contemplar las desventuras de su pueblo [...] (Martí 225)

$[\ldots]$ the lands all taken, sold, resold $[\ldots](35)$

[...] sus tierras ocupadas por aventureros [...]. (Martí 238)

His heart and thoughts filled with perplexities and fears... (92)

Él, con la pena grave de su pueblo [...]. (Martí 281) ISSN 0034-9631 (Impreso)
En algunas pocas ocasiones ocurren diferencias mayores en el léxico usado entre Hunt Jackson y Martí, instancias que podrían indicar errores de traducción, pero cuyos efectos siempre pertenecen al subtexto ideológico, dirigido hacia la cultura "nuestra" a través de una intensificación de los sentimientos o de una diferencia en la visión del mundo:

He comforted himself by thinking $[\ldots](25)$

¡...ya se vengaría de la forzosa separación...! (24: 228)

[...] those damned Indians [...] it's a shame they should have that spring. (289)

Da rabia de ver que [los indios] nos den con el agua corriente en la nariz. (24: 448)

My father and I have need of all the money we can earn. (100)

Mi padre y yo necesitamos trabajar en todo. (24: 286)

His skin [Alessandro's] was not a shade darker than Felipe's. (75)

El [color de la piel] de ella [Ramona] era poco más claro que el de él [Alejandro]. (24: 269)

En este último ejemplo en particular, queda claro que Martí cambia completamente la perspectiva: de una comparación original entre indio y mexicano, se vira hacia una comparación entre mestiza e indio - de "a shade darker" a más claro-de hecho confunde los comparanda y opone la sustancia de la comparación original cuyo efecto es el establecimiento de una diferencia entre Ramona y Alejandro (mestiza e indio) y no, como en Hunt Jackson, la presentación como razas equivalentes a Alessandro y Felipe (el indio y el mexicano).

A Martí ahora se le reconoce como uno de los innovadores de la prosa de fines del siglo XIX y uno de los primeros modernistas. Sus traducciones de algunas de las descripciones de la naturaleza y de Ramona misma se hacen tan líricas y ricas que pueden verse como expresiones implícitas no sólo sobre esos temas (naturaleza y mujer), sino también sobre la cuestión del estilo literario. Así, está muy clara su 'poetización' de estilo prosaico de Hunt Jackson, una poetización muy característica del modernismo. Martí hace uso mucho más marcado de los colores y de los efectos de la luz, y también hay una elegancia expresiva consciente; una simple "afternoon" se hace "una tarde dorada"; "the sun rose and let a flood of work-a-day light on the whole place" (50) se transforma en "el Sol, rey ya del valle, lo llenaba de luz" (24: 249), y los indios no dormirían "rolled up in their blankets, on the ground" como los tiene Hunt Jackson

Revista Iberoamericana, Vol. LXXIX, Núms. 244-245, Julio-Diciembre 2013, 777-795 ISSN 0034-9631 (Impreso) ISSN 2154-4794 (Electrónico) 
(56), sino "sin duda al libre amor del cielo, sin más cama que la tierra, ni más abrigo que sus frazadas" (24: 253$)$.

Es precisamente en esta 'poetización' del estilo donde ocurre un esporádico incremento léxico en la versión martiana: "It was exceedingly pleasant on the veranda" (106) se traduce como: "Le era grato vivir en aquella paz blanda, entre los pájaros alegres, al aire lleno de aroma, a la media luz de las enredaderas" (24:219). De nuevo, no sólo ocurre un cambio de la expresión impersonal hacia un impresión de placer sentida personalmente, sino que también se ve una percepción explícita de los sentidos auditivo, olfático y visual en la galería, con sus detalles - de nuevo indicativo de la preferencia martiana de la expresión directa sobre la descriptiva- $-{ }^{17}$ Así, Martí especialmente hace de Ramona 'nuestra novela' a través de embellecimientos de estilo en los pasajes no muy frecuentes donde elabora un texto más extenso en una forma cercana al romanticismo tardío y el modernismo temprano latinoamericanos:

These words were coming and going in her mind like refrains of songs which haun one's memory and will not be still. (160)

Yel dulcepensamiento aparecía tenaz para todos los rincones de sumente, iluminándola y calmándola, como los tonos de una música conocida que vuelven porfiados a la memoria y no quieren estarse quietos. (24: 338$)$

Alessandro's face haunted him [the judge who exonerated Alessandro's killer], and also the memory of Ramona's as she lay tossing and moaning in the wretched Cahuilla hovel. (321)

Más de una vez veía delante de sí la cara de Alejandro, con las heridas abiertas, como bocas que pedían justicia. Más de una vez le puso ante los ojos el remordimiento la escena desgarradora de Cajuela: el cadáver por tierra, Ramona tendida en la cama de aquella choza mísera, revolviéndose, mesándose el cabello, rezando el rosario, delirante [...] (24: 475)

Martí también adaptó su traducción de las inflecciones linguísticas de los personajes, y aunque no se sabe si lo hizo con intenciones ideológicas, las consecuencias se presentan a este nivel. Como lo indica Kate Phillips, en la novela de Jackson todos los personajes indígenas e hispánicos hablan "a heightened, formal English... [whereas] all the white Americans,... speak in dialects they have learned in their regions of

${ }_{17}$ Son evidentes aquí los ecos estilísticos de su novela Lucía Jerez, considerada como de las primeras innovadoras modernistas; por ejemplo, la primera página de esa novela reza: "Eran hermosas de ver, en quel domingo, en el cielo fulgente, la luz azul, y por entre los corredores de columnas de mármol, la magnolia elegante, entre las ramas verdes, las grandes flores blancas..." (18: 193). ISSN 0034-9631 (Impreso) Vol. LXXIX, Núms. 244-245, Julio-Diciembre 2013, 777-795 ISSN 2154-4794 (Electrónico) origin... [indicating] that they do not naturally belong in the land they have conquered" (Phillips 262) - como si fuera efectivamente el original una traducción 'exotizante'. Martí traductor, por el contrario, propone el habla de todos los personajes en el registro estándar de la lengua española. En particular, los episodios que tratan de 'Aunt Ri' Hyer, una intrépida mujer rural deTennessee que se mudó a California en busca de mejor fortuna, son reveladores. Esta señora llega siendo de importancia fundamenta en los esfuerzos de Ramona por recuperar la salud y la razón después del asesinato de Alessandro; es la/el única/o ciudadana/o de los Estados Unidos en la novela que tiene cualidades positivas; también es uno de los pocos no racistas. En el original de Hunt Jackson se dedican varios capítulos a los contactos de Ramona con Tía Ri, pero Martí, como instancia única, corta esos cuatro capítulos de manera drástica, resultando dos tan sólo. ${ }^{18}$ Además, en el original el habla de que Tía Ri pretende ser (de manera bastante artificiosa) de dialecto sureño estadounidense:

"Ef it ain't enny offence ter yeow, I allow I'd like ter know jest what 't is yeow air here ter dew fur these Injuns. I've got my feelin's considdable stirred up, bein' among 'em 'n' knowing this hyar one, thet's ben murdered. Hev ye got enny power to giv' 'em ennything -food or sech? They air powerful pore, most on 'em." (II, 291)

Como lo indica Berman entre otros (290), la traducción del dialecto ofrece problemas de varia índole, pero Martí traduce el habla como español estándar y así evita toda complicación. Irónicamente, al cortar grandes secciones de la actuación de Tía Ri (por ejemplo el pasaje citado arriba no aparece en la versión martiana), también disminuye la participación y por tanto el impacto que puede tener el único personaje norteamericano positivo - un efecto que apoya la intención de Martí por subrayar la personalidad generalizada negativa de los ciudadanos estadounidenses. Por cierto logra ese efecto en los que lean las dos versiones de la novela. ${ }^{19}$

En el 'Prólogo' a su traducción de la novela Misterio, Martí había dicho que "[t] raducir no es [...] mostrarse a sí propio a costa del autor, sino poner en palabra de la lengua nativa al autor entero, sin dejar ver en un solo instante la persona propia" ( 24 40). En oposición a este principio, queda claro de nuestra investigación que "Martí interviene sin cesar en sus textos como conciencia crítica" (Suárez de León 181) y así traiciona su propia visión del traductor, del que vio obligatoria la ausencia de su traducción. No sólo acomodó su texto a las diferencias culturales, sino que la visión martiana de los indígenas, del género novela, del género femenino, y de la escritura

\footnotetext{
${ }^{8}$ La versión original de la novela lleva los capítulos enumerados; Martí omite los números e inserta títulos; así no se hace claro de inmediato que su versión tiene tan sólo 24 capítulos vs 26 de la original.

19 Le agradezco a Hugh Hazelton de la Concordia University el haberme advertido sobre la anomalía, as como tambien las discusiones tenidas sobre esta cuestion.

2017 Revista Iberoamericana, Vol. LXXIX, Núms. 244-245, Julio-Diciembre 2013, 777-795 ISSN 0034-9631 (Impreso) ISSN 2154-4794 (Electrónico)
} 
como estilo se presenta como un subtexto evidente a través toda la obra, subtexto que domina por sobre la precisión lingüística. Estas fueron perspectivas profundamente pensadas por Martí en su proceso de traducir-recordemos su metáfora de 'cavar' citado arriba-y aspectos intrínsecos de la obra, que la hacen una zona de contacto (lingüístico, cultural) entre Latinoamérica y Norte América. En diálogo con Helen Hunt Jackson y con sus propias obras, su 'transpensamiento' se constituye en componente activo en la construcción de sentido de la obra. Así, para concluir valga la cita de Fernández Retamar, de que "estamos en presencia de una obra transpensada, recreada por Martí: una obra que debemos considerar también suya" (425-426).

\section{OBRAS CITADAS}

Arencibia Rodríguez, Lourdes. El traductor Martí. Pinar del Río: Editorial Hermanos Loynaz, 2000.

Barredas Sánchez, Maia. "Ramona, un nuevo movimiento en la ficción prolongada". 2001, 13p. Unpublished manuscript provided by author.

Berman, Antoine, "Translation and the Trials of the Foreign". The Translation Studies Reader. Lawrence Venuti, ed. London: Routledge, 2000. 284-297.

Colombi, Beatriz. "José Martí: traducir, transpensar". Legados de José Martí en la crítica latinoamericana. Susana Zanetti, comp. La Plata: Universidad Nacional de la Plata, 1999. 19-31.

Cruz, Mary. "Una novela como arma de lucha: Martí y su traducción de Ramona de Helen Hunt Jackson". Granma (enero 20, 1975): 2.

Cuesta, Leonel-Antonio de la. Martí, traductor. Salamanca: Pontificia Universidad de Salamanca, 1996.

DeLyser, Dydia. Ramona Memories. Tourism and the Shaping of Southern California. Minneapolis: U of Minnesota P, 2005.

Dorris, Michael. "Introduction”. Helen Hunt Jackson, Ramona. New Hork: Signet, 2002 (1988): v-xvii.

Fernández Retamar, Roberto. "Sobre Ramona de Helen Hunt Jackson y José Martí." Helen Hunt Jackson, Ramona. José Marti, trad. La Habana: Ediciones Huracán, 1975. 417-426.

González Patricio, Rolando. "El Tratado Guadalupe Hidalgo en los orígenes de una historia compartida". Anuario del Centro de Estudios Martianos 21 (1998): 187-194.

Hunt Jackson, Helen [Fiske]. Ramona, A Story (1884). 1988. New York: Penguin Eds. 2002.

Kerekes,Ana-Maria. Podery belleza de la palabra: Análisis de la traducción martiana de la novela Ramona de Helen Hunt Jackson. MAThesis: Concordia University, 2009.

Lomas, Laura. Translating Empire. José Martí, Migrant Latino Subjects and American Modernities. Durham: Duke UP, 2008.

17. Revista Iberoamericana, Vol. LXXIX, Núms. 244-245, Julio-Diciembre 2013, 777-795 ISSN 0034-9631 (Impreso) ISSN 2154-4794 (Electrónico)
McKee Irwin, Robert. “Ramona and PostnationalistAmerican Studies: On 'Our America' and the Mexican Borderlands." American Quarterly 55/4 (2003): 539-567.

Martí, José. Obras completas. La Habana: Editorial de Ciencias Sociales, 1975.

Martínez, Mayra Beatriz. Martí: Eros y mujer. La Habana: Pinos Nuevos, 2005.

Montero, Oscar. José Martí, an Introduction. New York: Palgrave MacMillan, 2004

Paz, Octavio. "Literatura y literalidad". Excursiones/Incursiones. Dominio extranjero. México: FCE, 1994. Tomo II. 65-74.

Phillips, Kate. Helen Hunt Jackson. A Literary Life. Berkeley: U of California P, 2003.

Rodríguez Morell, Jorge Luis. "Razones para una metodología de análisis de la traducción martiana en Ramona". Anuario del Centro de Estudios Martianos 18 (1995-96): 133-140

Schulman, Iván. "Transtextualización y socialización fictivas: Misterio y Ramona". Anuario del Centro de Estudios Martianos 13 (1990): 288-298

"Texto/transtexto: Reconsideraciones sobre Martíy la novela moderna". Anthropos. Revista de Documentación Científica de la Cultura 169 (nov.-dic.1995): 72-79.

Suárez de León, Carmen. "Martí: Traductor de textos, traductor de mundos". Anuario del Centro de Estudios Martianos 25 (2002): 177-190.

Toledo Sande, Luis. Cesto de llamas: Biografía de José Martí. La Habana: Editoria de Ciencias Sociales, 1996.

Sarracino, Rodolfo. José Martí y el Caso Cutting. La Habana: Centro de Estudios Martianos, 2008.
Revista Iberoamericana, Vol. LXXIX, Núms. 244-245, Julio-Diciembre 2013, 777-795 ISSN 0034-9631 (Impreso) 
